\title{
Síndrome Progeria y su implicancia anestesiológica: Reporte de un caso y revisión de la literatura
}

\author{
Goldberg L. ${ }^{1}$, Murinigo A. ${ }^{1}$, Navarro Salgado M. ${ }^{1}$, Cury A. ${ }^{1}$, Latini C. ${ }^{1}$, García Picasso D. ${ }^{1}$, Daud O. ${ }^{1}$ \\ 1 Hospital Bernardino Rivadavia, CABA, Argentina.
}

Introducción: El Síndrome Progeria o de Hutchinson-Gilford es una condición genética autosómica dominante extremadamente rara que causa envejecimiento prematuro. Se caracteriza por falla en el crecimiento, pérdida de la grasa subcutánea, baja estatura, alopecia, exoftalmos, micrognatia, retrognatia, rigidez cervical, fragilidad capilar, progresiva aterosclerosis con las posibles complicaciones cardio y cerebrovasculares.

Descripción del caso: Paciente de sexo masculino de 14 años con diagnóstico de Síndrome Progeria, en plan quirúrgico para cirugía de cataratas. Presenta como antecedentes hipertensión arterial y agammaglobulinemia. Mallampati clase 4 y distancia tiromentoniana de $3 \mathrm{~cm}$. Está medicado con enalapril, cilostazol y aspirina. Electrocardiograma: ritmo sinusal, 86 lpm, QTc $388 \mathrm{mseg}$, ST-T isonivelado. Ecocardiograma Doppler: función sistólica del ventrículo izquierdo conservada, sin cardiopatía estructural. Laboratorio normal.

Se decide realizar anestesia general balanceada. Inducción con sevofluorano $8 \%$, fentanilo $2 \mathrm{mcg} / \mathrm{kg}$, rocuronio 0,5 $\mathrm{mg} / \mathrm{kg}$. Ante la posibilidad de una probable vía aérea dificultosa, se dispuso de máscaras laríngeas de distintos tamaños y videolaringoscopio. Presentó dificultad en la inserción de accesos venosos periféricos debido a su fragilidad capilar de base. Se realizó laringoscopía directa visualizandose un Cormack-Lehane grado 3 e intubación orotraqueal utilizando laringoscopio articulado y guia bougie/Eschmann. El mantenimiento anestésico se realizó con sevofluorano $1 \%$ y remifentanilo $0,3 \mathrm{mcg} / \mathrm{kg} / \mathrm{min}$. El monitoreo neuromuscular intraoperatorio se realizó mediante tren de cuatro (TOF). Al finalizar el procedimiento, el paciente presentaba 2/4 respuestas motoras (Bloqueo Moderado), por lo que se decide la reversión con $2 \mathrm{mg} / \mathrm{kg}$ de sugammadex.

Comentarios y Discusión: Las características de este tipo de paciente plantean un verdadero desafío al anestesiólogo. En primer lugar porque las particularidades de los mismos mezclan características tanto pediátricas como de adultos, sumado al resto de sus comorbilidades, por lo cual se debe contar con un anestesiólogo que posea conocimientos en ambos campos. En segundo lugar, se debe tener presente la conformación de la vía aérea, lo que obliga a contar con adecuados dispositivos para lograr la intubación. El propósito del caso es presentar las diversas situaciones con las cuales un anestesiólogo puede encontrarse con esta clase de paciente.

https://doi.org/10.25237/congresoclasa2019.68 